\title{
Literature Review of the Outcome after One-Stage Transanal Endorectal Pull-Through Procedure for Hirschsprung's Disease in Children
}

\author{
Irene Ortiz-Rubio ${ }^{1 *}$, María Pérez-Aguilera ${ }^{2 * \#}$, Christina Granéli ${ }^{3,4}$, \\ Pernilla Stenström ${ }^{3,4}$, Einar Arnbjörnsson ${ }^{3,4}$ \\ ${ }^{1}$ Autonomous University of Barcelona, Barcelona, Spain \\ ${ }^{2}$ University of Seville, Seville, Spain \\ ${ }^{3}$ Department of Paediatric Surgery, Skåne University Hospital, Lund, Sweden \\ ${ }^{4}$ Lund University, Lund, Sweden \\ Email: iortiz1906@gmail.com, " maghalit@hotmail.com, christina.graneli@skane.se, \\ pernilla.stenstrom@med.lu.se, einar.arnbjornsson@telia.com
}

Received January 20, 2013; revised February 22, 2013; accepted March 3, 2013

Copyright (C) 2013 Irene Ortiz-Rubio et al. This is an open access article distributed under the Creative Commons Attribution License, which permits unrestricted use, distribution, and reproduction in any medium, provided the original work is properly cited.

\begin{abstract}
Background: Transanal endorectal one-stage pull-through (TERPT) procedure in children with Hirschsprung's disease (HD) is frequently used worldwide. In order to give the families realistic expectations and to plan the medical care for the years after TERPT, the long term outcome is of great importance. Aim: To collect information on the long term outcome reported after one stage TERPT procedure for HD in children 0 - 15 years. Method: A literature review on the outcome of planned TERPT from 2005 through 2012 was carried out. Information was collected on the number of daily stools a few months postoperatively, incontinence and constipation and the measures taken to deal with these. Results: The reports are few and prospective studies were missing. The results show an initial high frequency of daily stools, $12 \%$ had later abnormal stool patterns, $21 \%$ had fecal incontinence and $10 \%$ had problems with constipation. Conclusion: In order to compare the long term outcome, it would be desirable to have uniform regular reports on the daily frequency of passed stools, incontinence and constipation during the first years after TERPT. Such knowledge would be of importance for the information given to the guardians of children with HD preoperatively to TERPT and in the planning of the future care. The findings can, furthermore, provide a benchmark for the outcome from a single centre.
\end{abstract}

Keywords: Transendorectal Pull-Through (TERPT); Hirschsprung's Disease (HD); Outcome; Incontinence; Constipation

\section{Introduction}

The transanal endorectal pull-through (TERPT) technique for Hirschsprung's disease (HD) was introduced in 1998 [1]. The TERPT procedure was intended to be less invasive than previously used procedures for HD such as Duhamel's operation. The fact that a minimal intraabdominal dissection is included only in the TERPT intervention, should lead to less postoperative pain and shorter hospitalization. Since there are no scars in the perineum the cosmetic results are good and the only visual scars may be on the abdominal wall after minimal invasive surgery to assist performing the one stage TERPT.

"I. Ortiz-Rubio and M. Pérez-Aguilera equally contributed to this work. ${ }^{\#}$ Corresponding author.
Children with HD may have to cope with a lot of symptoms, sometimes lifelong, as a result of a shortened intestine, possible damage to the surrounding structures in the pelvic floor and because that the left bowel may be dysfunctional. When informing the child's guardians about this possible handicap, the question that arises is which problem the child is going to have both in the postoperative period and in the future. Therefore it is of interest to collect knowledge from the literature about what has been reported on the bowel symptoms after TERPT in patients with HD. It is, for example, of great interest to know whether the children have problems with incontinence or severe constipation as well as the frequency of stools as long term results. Such knowledge would be useful for supporting the information given to 
the families of the children with HD as well as in the planning of the need of medical care after TERPT.

Aim: This review was undertaken to gather information on the long term outcome after TERPT in children with HD. Information was collected regarding the daily frequency of stools after three, six and twelve months postoperatively as well as the prevalence of incontinence and constipation. We are not aware of similar reports in the literature.

\section{Method}

A literature review of reported TERPT operations on children with HD was carried out. MEDLINE and EMBASE were searched for all studies reporting on children who had undergone surgical intervention for HD using TERPT between 2005 through 2012. This period was selected with a beginning 7 years after the publication of the TERPT method [1] hoping to find reports on longterm results. Only reports written in English were included.

Reports on planned TERPT operations were included only. Information was collected with particular emphasis on the outcome measured in the frequency of daily stools, rate of incontinence and constipation and any operative intervention to cope with these problems. The definition of "abnormal stool frequency" was missing. Detailed general information was recorded regarding the reported type of study, children's age and gender and intraoperative details including the length of the bowel affected by HD.

The search terms used were: Transanal endorectal pullthrough, Hirschsprung's disease, Newborns, Outcome: incontinence and constipation.

The reference list from the retrieved articles was reviewed for additional reports on children undergoing TERPT. All published reports and abstracts presented at meetings were evaluated.

\section{Results}

Of 14 published articles 11 were included [2-15]. A total of 297 children were included in the selected material and the demography of the children included in the survey is summarized in Table 1. The results regarding stool frequency, incontinence and constipation are summarized in different ways in Tables 2 and $\mathbf{3 .}$

\subsection{Constipation}

We noted that there are more reported problems postoperatively when the reconstructive surgery is performed in older children than in younger. In one report on children operated on at ages from 17 days to 3 months the authors did not disclose any constipation problems [15]. This is to be compared with a report describing 4 (20\%)
Table 1. Information available on the children reported on in the included publications.

\begin{tabular}{cc}
\hline Number of children & 297 (24 not gender specified) \\
\hline Females/Males (\%) & $98(36 \%) / 175(64 \%)$ \\
Female/Male ratio & $1 / 1.8$ \\
$\begin{array}{c}\text { Duration of observation, } \\
\text { MEDIAN (range) }\end{array}$ & 3 years (1 month - 15 years) \\
\hline
\end{tabular}

Table 2. A summary of the reports on normal versus abnormal stool frequency as well as the frequency of incontinence and constipation in 277 children included in eight reports on postoperative outcome after TERPT operation for Hirschsprung's disease.

\begin{tabular}{lccc}
\hline & $\begin{array}{c}\text { Number of } \\
\text { reports }\end{array}$ & $\begin{array}{c}\text { Number of } \\
\text { children (\%) }\end{array}$ & $\begin{array}{c}\text { Total number } \\
\text { of children } \\
\text { reported }\end{array}$ \\
\hline Stool frequency & $5^{*}$ & & 191 \\
-normal & & $164(86 \%)$ & \\
-abnormal & & $27(14 \%)$ & \\
Incontinence & $4^{* *}$ & $22(21 \%)$ & 105 \\
Constipation & $6^{* * *}$ & $12(10 \%)$ & 118 \\
\hline
\end{tabular}

*Aslan $2007(\mathrm{n}=22), \operatorname{Kim} 2009(\mathrm{n}=61)$, Tannuri $200(\mathrm{n}=24)$, Zang 2007 $(\mathrm{n}=58)$, Obermayr $2009(\mathrm{n}=25) ;{ }^{* *}$ Aworanti $2012(\mathrm{n}=16)$, Obermayr $2009(\mathrm{n}=25)$, Tannuri $2009(\mathrm{n}=24)$, Zakaria 2012 $(\mathrm{n}=40) ;{ }^{* * *}$ Aslan 2007 $(\mathrm{n}=22)$, Ates $2007(\mathrm{n}=15)$, Aworanti $2012(\mathrm{n}=16)$, El-Sawaf $2007(\mathrm{n}=$ 16), Obermayr $2009(\mathrm{n}=25)$, Tannuri $2009(\mathrm{n}=24)$.

of the operated children with constipation problems when they were 3 years or older. Two of these were resolved using bowel management; one with laxatives and one with enema [2]. In another report regarding children 3 years or older the authors reported a different result with just 1 patient $(23-43 \%)$ with constipation [11]. These results are comparable with another study showing that $25 \%$ of children between 3 months and 15 years had problems with constipation [14]. These results were also supported by reports describing more constipation problems among adolescents and younger patients [8]. Another study that described constipation after TERPT showed that these problems could be treated satisfactorily with laxatives only. Unfortunately the authors did not state the age of the patients at the time of surgery [10]. When it comes to correlating the outcome of the patients with their age, one report provides information by analysing two groups where one includes younger children (6 months -3.5 years) and the other one older $(3.5-13$ years). The problem is that the authors do not specify which patients had incontinence or constipation; they focused on stool problems; including both. They found a total of 5 children with problems but there was not a significantly higher number in either age group [3].

In conclusion, the results should be classified by the age at which the surgery is performed. The follow-up 
Table 3. The number of daily stools correlated to the duration of observation in $\mathbf{5 6}$ reported children with Hirschsprung's disease operated on with TERPT.

\begin{tabular}{|c|c|c|c|c|}
\hline \multirow{2}{*}{ Observation times } & \multicolumn{3}{|c|}{ Reported number of daily stools } & \multirow{2}{*}{ Number of children } \\
\hline & Ates $2007 \mathrm{~N}=15$ [15] & Obermayr $2009 \mathrm{~N}=25[10]$ & Pratap $2007 \mathrm{~N}=19$ [12] & \\
\hline 3 months & & & 5 & 19 \\
\hline 6 months & 2 & & & 15 \\
\hline 12 months & & & $3(1-6)$ & 19 \\
\hline$>3$ years & & $3(1-5)$ & & 25 \\
\hline
\end{tabular}

time is important. The longer the follow-up has been the better the results. However the majority of the studies does not register the rate of constipation or do not report them in the same way.

\subsection{Incontinence}

Incontinence was reported in 4 of the papers which included 105 children. 22 of these 105 studied children were reported incontinent $[3,10,13,14]$. One report shows that 11 out of 16 patients $(69 \%)$ had incontinence problems [14]. Another report regarding patients between 10 days and 6 years of age says that 5 out of 25 patients (21\%) suffered from incontinence [13]. One report provided information about two different age groups and the number of patients with incontinence. The authors divided the children into a younger group (6 months - 3.5 years) that had no incontinence and an older group (3.5 13 years) where some patients had problems with their stools. Unfortunately the exact number of patients who suffered from incontinence was not reported since the authors did not specify which patients had incontinence or constipation, as they focused only on stool problems [3].

One report found a correlation between trisomy 21 and incontinence described in 1 out of 20 patients $(5 \%)$ [10].

\subsection{Frequency of Stools}

The reports on the number of daily stools passed have not been presented in a manner making them comparable and thus we were unable to make a summary. This is an outcome that many authors do not report. Thus, we gained too little information to draw any real conclusion regarding the correlation between TERPT and amount of daily stools passed.

The definition of normal stool frequency was vague and differed between the studies. The frequency of stools reported in the majority of the articles shows that on the whole it was considered normal and there are only a low percentage of reported children with abnormalities in their stool patterns. One study of 61 children reports that
56 patients $(91 \%)$ had normal stool patterns after 9.4 6.2 weeks [4]. In another study almost all of the children had normal stool frequency (54/58). Furthermore, the younger the patient at surgery, the earlier the frequency of stools is normalized [5]. One study shows that $95 \%$ of operated children were continent at the endpoint of follow-up [10]. Another study shows similar results where $80.5 \%$ of 22 children had normal intestinal function [11]. In the last study 17 out of 24 patients $(70.8 \%)$ had complete continence and 5 of the same patients $(20.8 \%)$ had partial continence [13].

The number of daily stools passed is only reported in 3 of 11 included reports. In one of the studies it was shown that after a median follow-up of 35 months the median frequency of bowel movements was 3/day (1 - 5/day) [10].

\section{Discussion}

The results of the literature survey of reports on TERPT for children with HD, with particular emphasis on the frequency of incontinence and constipation, revealed that the rate of both was reported to be low after the performed operation. However, in spite of this low frequency, the problem of incontinence and constipation exits. Reports on operative interventions to relieve the problems of incontinence and constipation are missing in the included papers. There are no randomized studies and reports with comparisons between different operative methods are few [16-19]. There were no prospective studies, only retrospective.

The duration of observation time reported in the publications is relatively short, 3 years (range 1 month - 15 years). The complications of incontinence or constipation may be discovered later, although the majority of these problems came to light within the first four years postoperatively. Thus, the follow up time is too short to evaluate the final outcome in this regard. The same applies to the evaluation of functional bowel movement. The studies included in this paper reported results from a pediatric population only. This population represents a wide age range from newborns to 15 -year-olds, while the great majority of the children included here are less than 
three years of age.

In this report, re-operations and postoperative complications like enterocolitis are not included. These complications have already been reported in well performed literature reviews $[16,19]$.

A review of the literature is necessary to evaluate both qualitatively and quantitatively the results of different studies. It is important, however, to address the limitations of this literature review. There is a bias in the report due to several reasons. In this context it is important to bear in mind a no publication bias, particularly in a review based on published studies. The studied material is, moreover, biased by the fact that the authors do not report their results in a way that makes them comparable with other authors' results. Thus, a considerable number of children as well as several data have not been included. Furthermore, there may be a variation in inclusion criteria, study type, lack of randomization, treatment protocol, and outcome assessment between the studies. The databases MEDLINE and EBASE were the only ones used which can mean that publications in some open access and other indexed databases are missed.

In this report, an attempt is made to select outcome measures that are as absolute as possible and describe the child's situation during the postoperative period. These parameters that are of great importance to the parents can become influenced by local traditions, and different studies may have had slightly different defining criteria for the outcome measures. The role of the child's guardians is of the utmost importance for disclosing minor problems or concealing major problems by the way they take care of their child.

The length of the resected bowel in the reported cases was only $20.5 \mathrm{~cm}$, thus representing the group of children suitable for the TERPT operation. This excluded those where laparoscopy or laparotomy is used to facilitate the intervention due to a preoperative clinical suspicion of a longer malformed bowel. It was not possible to differentiate the length of the aganglionotic segment from rectum, recto-sigmoideum and recto descendens and longer, due to missing data in most of the studies. The children left with a very short bowel are thereby excluded and those with the most severe incontinence problems may have been excluded.

In conclusion, the review provides some information on the incidence of incontinence and constipation after the TERPT procedure. The results of this review are of importance in preoperative counseling and when planning for the postoperative care of children with HD undergoing the TERPT procedure. However, it is obvious that solid information on the outcome after TERPT operation for HD in children is missing in the literature. We urge the authors of reports on children with HD operated on with the TERPT procedure to report on the outcome in some sort of standardized fashion to enable comparison with other reported groups of children in the same situation.

\section{Acknowledgements}

Gillian Sjödahl, Lexis English for Writers, Lund, Sweden, for linguistic revision of the manuscript.

\section{REFERENCES}

[1] De la Torre-Mondragón and J. A. Ortega-Salgado, "Transanal Endorectal Pull-Through for Hirschsprung's Disease," Journal of Pediatric Surgery, Vol. 34, No. 3, 1998, pp. 1283-1286.

[2] M. I. El-Sawafa, R. A. Drongowski, J. N. Chamberlain, A. G. Coran and D. H. Teitelbaum, "Are the Long-Term Results of the Transanal Pull-Through Equal to Those of the Transabdominal Pull-Through? A Comparison of the 2 Approached for Hirschprung Disease," Journal of Pediatric Surgery, Vol. 42, No. 1, 2007, pp. 41-47. doi:10.1016/j.jpedsurg.2006.09.007

[3] O. M. Zakaria, "Bowel Function and Fecal Continence after Soave's Trans-Anal Endorectal Pull-Through for Hirschsprung's Disease: A Local Experience," Updates in Surgery, Vol. 64, No. 2, 2012, pp. 113-118. doi:10.1007/s13304-012-0140-9

[4] H. Y. Kim and J. T. O, "Stabilization Period after 1-Stage Transanal Endorectal Pull-Through Operation for Hirschsprung Disease," Journal of Pediatric Surgery, Vol. 44, No. 9. 2009, pp. 1799-1804.

doi:10.1016/i.jpedsurg.2008.10.070

[5] S. C. Zhang, Y. Z. Bai, W. Wang and W. L. Wnag, "Clinical Outcome in Children after Transanal 1-Stage Endorectal Pull-Through Operation for Hirschsprung's Disease," Journal of Pediatric Surgery, Vol. 40, No. 8, 2005, pp. 1307-1311. doi:10.1016/j.jpedsurg.2005.05.016

[6] N. Fujiwara, K. Kaneyama, T. Okazaki, G. J. Lane, Y. Kato, H. Kobayashi and A. Yamataka, "A Comparative Study of Laparoscopy-Assisted Pull-Through and Open Pull-Through for Hirschsprung's Disease with Special Reference to Postoperative Fecal Continence," Journal of Pediatric Surgery, Vol. 42, No. 12, 2007, pp. 2071-2074. doi:10.1016/i.jpedsurg.2007.08.033

[7] Y. Huang, S. Zheng and X. M. Xiao, "A Follow-Up Study on Postoperative Function after a Transanal Soave 1-Stage Endorectal Pull-Through Procedure for Hirschsprung's Disease," Journal of Pediatric Surgery, Vol. 43, No. 9, 2008, pp. 1691-1695. doi:10.1016/j.jpedsurg.2007.12.053

[8] R. J. Rintala and M. P. Pakarinen, "Long-Term Outcomes of Hirschsprung's Disease," Seminars in Pediatric Surgery, Vol. 21, No. 4, 2012, pp. 336-343. doi:10.1053/j.sempedsurg.2012.07.008

[9] I. Jester, S. Holland-Cunz, S. Loff, S. Hosie, K. Reinshagen, H. Wirth, M. Ali and K. L. Waag, "Transanal PullThrough Procedure for Hirschsprung's Disease: A 5-Year Experience," European Journal of Pediatric Surgery, Vol. 19, No. 2, 2009, pp. 68-71. 


\section{doi:10.1055/s-2008-1039052}

[10] F. Obermayr, P. Szavay, R. Beschorner and J. Fuchs, "Outcome of Transanal Endorectal Pull-Through in Patients with Hirschsprung's Disease," European Journal of Pediatric Surgery, Vol. 19, No. 4, 2009, pp. 220-223. doi:10.1055/s-0029-1220682

[11] M. K. Aslan, I. Karaman, A. Karaman, D. Erdoğan, Y. H. Cavuşoğlu and O. Cakmak, "Our Experience with Transanal Endorectal Pull-Through in Hirschsprung's Disease," European Journal of Pediatric Surgery, Vol. 42, No. 7, 2007, pp. 335-339. doi:10.1055/s-2007-965447

[12] A. Pratap, V. C. Shakya, B. K. Biswas, A. Sinha, A. Tiwari, C. S. Agrawal and S. Adhikary, "Single-Stage Transanal Endorectal Pull-Through for Hirschsprung's Disease: Perspective from a Developing Country," Journal of Pediatric Surgery, Vol. 42, No. 3, 2007, pp. 532-535. doi:10.1016/i.jpedsurg.2006.10.049

[13] A. C. Tannuri, U. Tannuri and R. L. Romão, “Transanal Endorectal Pull-Through in Children with Hirschsprung's Disease-Technical Refinements and Comparison of Results with the Duhamel Procedure," Journal of Pediatric Surgery, Vol. 44, No. 4, 2009, pp. 767-772.

[14] O. M. Aworanti, D. T. McDowell, I. M. Martin, J. Hung and F. Quinn, "Comparative Review of Functional Outcomes Post Surgery for Hirschsprung's Disease Utilizing the Paedia-Tric Incontinence and Constipation Scoring System," Pediatric Surgery International, Vol. 28, No. 11,
2012, pp. 1071-1078.

[15] O. Ateş, G. Hakgüder, Y. Kart, M. Olguner and F. M. Akgür, "The Effect of Dilated Ganglionic Segment on Anorectal and Urinary Functions During 1-Stage Transanal Endorectal Pull-Through for Hirschsprung's Disease," Journal of Pediatric Surgery, Vol. 42, No. 7, 2007, pp. 1271-1275. doi:10.1016/j.jpedsurg.2007.02.020

[16] E. Ruttenstock and P. Puri, "Systematic Review and MetaAnalysis of Enterocolitis after One-Stage Transanal PullThrough Procedure for Hirschsprung's Disease," Pediatric Surgery International, Vol. 26, No. 11, 2010, pp. 11011105. doi:10.1007/s00383-010-2695-1

[17] A. Gunnarsdóttir, L. T. Larsson and E. Arnbjörnsson, "Transanal Endorectal vs. Duhamel Pull-Through for Hirschsprung's Disease," European Journal of Pediatric Surgery, Vol. 20, No. 4, 2010, pp. 242-246. doi:10.1055/s-0030-1252006

[18] C. Grano, D. Aminoff, F. Lucidi and C. Violani, "LongTerm Disease-Specific Quality of Life in Children and Adolescent Patients with ARM," Journal of Pediatric Surgery, Vol. 47, No. 7, 2012, pp. 1317-1322. doi:10.1016/i.jpedsurg.2012.01.068

[19] A. Lopera, P. Stenström, M. Anderberg and E. Arnbjörnsson, "Literature Review of the Frequency of Reoperations after One Stage Transanal Endorectal Pull-Through Procedure for Hirschsprung's Disease in Children," Surgical Science, Vol. 3, No. 6, 2012, pp. 290-294. doi:10.4236/ss.2012.36058 